\title{
Therapeutic benefit of aripiprazole-olanzapine combination in the treatment of senile Alzheimer's disease complicated by mental disorders
}

\author{
Na Zheng*, Ning Wang, Ji-Min Jia \\ Department of Psychiatry, Binzhou People's Hospital, Binzhou 256600, PR China
}

*For correspondence: Email: zhengnaii@163.com

Sent for review: 5 October 2019

Revised accepted: 24 January 2020

\begin{abstract}
Purpose: To determine the clinical efficacy of aripiprazole-olanzapine combination treatment in elderly Alzheimer's disease complicated with mental disorders.

Methods: Ninety-two elderly patients with Alzheimer's disease and mental disorders who were admitted to Binzhou People's Hospital, were enrolled in the study. They were randomized into control and study groups. Control group was treated with olanzapine, while the study group was treated with aripiprazole as an adjuvant therapy in addition to olanzapine. The clinical efficacy, scores on different scales (MMSE, ADAS-cog, CDR, ADL, NPI and CMAI), and incidence of adverse reactions were determined.

Results: The overall degree of response was significantly higher in the study group than in the control group ( $p$ < 0.05). There were no significant differences in MMSE, ADAS-cog, CDR, ADL, NPI and CMAI scores between the two groups before treatment $(p>0.05)$. The MMSE score of the study group was significantly higher than that of the control group, and the scores in the other scales in the study group were significantly lower after treatment $(p<0.05)$. The study group had significantly lower incidence of adverse reactions than control group $(p<0.05)$.

Conclusion: Aripiprazole-olanzapine combination has significant therapeutic benefit in the treatment of elderly Alzheimer's disease patients complicated with mental disorders. It promotes recovery of neurological function, as well as produces a lower incidence of adverse reactions.
\end{abstract}

Keywords: Aripiprazole, Olanzapine, Alzheimer's disease, Mental disorders

\begin{abstract}
This is an Open Access article that uses a fund-ing model which does not charge readers or their institutions for access and distributed under the terms of the Creative Commons Attribution License (http://creativecommons.org/licenses/by/4.0) and the Budapest Open Access Initiative (http://www.budapestopenaccessinitiative.org/read), which permit unrestricted use, distribution, and reproduction in any medium, provided the original work is properly credited.

Tropical Journal of Pharmaceutical Research is indexed by Science Citation Index (SciSearch), Scopus, International Pharmaceutical Abstract, Chemical Abstracts, Embase, Index Copernicus, EBSCO, African Index Medicus, JournalSeek, Journal Citation Reports/Science Edition, Directory of Open Access Journals (DOAJ), African Journal Online, Bioline International, Open-J-Gate and Pharmacy Abstracts
\end{abstract}

\section{INTRODUCTION}

Alzheimer's disease is a progressive, multi-site and multi-nervous function degenerative disease which often occurs in the pre-elderly or elderly population. The main clinical manifestations of Alzheimer's disease are cognitive function impairment, decline in social cognitive function and non-cognitive neuropsychological behavior, among which neuropsychological behavior is the most serious [1,2]. Studies show that Alzheimer's disease patients who are more than 60 years old have different degrees of psycho- behavioral symptoms which affect their lives and those of their family members $[3,4]$. The incidence of elderly Alzheimer's disease complicated with mental disorders increases with age [5]. At 
present, drugs are used to relieve the psychobehavioral symptoms of Alzheimer's disease [6].

Olanzapine, a 5-hydroxytryptamine/dopamine antagonist, has a good therapeutic effect on organic mental disorders, but its effect when used alone is not very satisfactory [7]. A study has shown that atypical anti-psychotic drugs have good compliance and efficacy in the treatment of Alzheimer's disease [8]. Aripiprazole, a new atypical antipsychotic drug, alleviates symptoms of mental disorders reduces negative symptoms, and improves cognitive function of patients [9]. However, there are no reports on the combined use of the two drugs in clinics.

Thus, this study was carried out to determine the clinical effect of aripiprazole-olanzapine combination in the treatment of elderly Alzheimer's disease complicated with mental disorders, so as to provide new clinical approaches in the treatment of the disease.

\section{METHODS}

\section{Subjects}

Ninety-two elderly patients with Alzheimer's disease and mental disorders who were admitted to our hospital from August 2017 to August 2018 were selected as the study subjects. The patients were randomly grouped into control and study groups, with 46 patients in each group. The study was approved by the Medical Ethics Committee of Binzhou People's Hospital (approval no. ZN20170806), and it was carried out in line with the guidelines contained in the Declaration of Helsinki [10].

The inclusion criteria were: (1) compliance with the diagnostic criteria of Alzheimer's disease in the Classification and Diagnosis Criteria for Mental Disorders of China formulated by the Psychiatric Branch of the Chinese Medical Association [11]; (2) patients with different degrees of mental and behavioral symptoms, dementia behavior scale score $>60$ points, and Alzheimer's Disease Rating Scale (BEHAVE-AD) score $\geq 8$ points; (3) patients who did not take anti-psychotic drugs one month before admission, and (4) signing of informed consent by patients and their family members, the exclusion criteria included: (1) patients with severe heart, liver, kidney and hematopoietic dysfunction; (2) patients with Parkinson's syndrome caused by cerebrovascular diseases or encephalitis, and (3) patients with severe physical diseases, limb dysfunction and malignant tumors.

\section{Therapeutic methods}

The control group was treated with olanzapine (Jiangsu Hansoh Pharmaceutical Co. Ltd, China; batch number: H20052688) at a dose of $2.5 \mathrm{mg}$ orally, once in the evening. The study group was treated with aripiprazole (Zhejiang Dazhong Pharmaceutical Co. Ltd, China; batch number: H20061304) combined with olanzapine. The administration of olanzapine in the study group was similar to that in the control group. Aripiprazole was given orally at a dose of $2.5 \mathrm{mg}$, once in the evening. Two weeks was taken as one treatment course, and the treatment lasted for four treatment courses.

During the treatment, patients in the two groups were given comprehensive nursing care. They received appropriate guidance, and were encouraged and assisted to complete their daily activities such as dressing, eating and defecation, especially if they could not accomplish them on their own. Auxiliary nursing was also provided. The patients underwent relevant examination under assistance and were warned to take their drugs on time. Moreover, their family members of the patients were informed that it was important for the patients to take their medications on time. The third measure was psychological nursing. Medical staff communicated with the patients so as to understand their ideas, actively guide them to participate in collective activities, and prevent them from developing psychological disorders. The last one was cognitive nursing. The patients and their families were taught health knowledge and disease-related knowledge; special training of memory and cognitive ability was developed for the patients to slow down their decline.

\section{Treatment indicators}

The mental status of patients was evaluated with mini-mental state examination (MMSE) in terms of visual space, language, delayed memory, computational ability and attention, immediate memory, location orientation and time orientation. The total score was 30 points, and high scores indicated better intelligence. The cognitive function was evaluated using Alzheimer's disease Assessment ScaleCognitive section (ADAS-Cog) which comprised 12 items, including visual space, language and orientation. The total score was 75 points, and low scores indicated better cognitive function. Cognitive impairment was evaluated using clinical dementia rating (CDR). The evaluation was made on aspects of memory, judgment ability, ability to solve problems and self-care 
ability. High scores indicated more serious cognitive impairment.

Patients' daily living self-care ability was evaluated using activity of daily living scale (ADL). The lower the score, the stronger the patients' daily living self-care ability. The neuropsychiatric symptoms were evaluated with Cohen-Mansfield Agitation Inventory (CMAI). The evaluation content included ten neuropsychiatric categories such as abnormal nocturnal behavior, abnormal movement, emotional apathy, irritability/instability and depression. The higher the score, the worse the psychiatric symptoms. The mental status of patients was evaluated using neuropsychiatric inventory (NPI). The higher the score, the worse the psychiatric symptoms. Incidence of adverse reactions such as dry mouth, insomnia, somnolence, constipation and weight gain after treatment were recorded.

\section{Criteria for evaluating efficacy}

Therapeutic effect was evaluated using BEHAVE-AD [12]. The treatment was deemed significantly effective if the reduction in score was more than $60 \%$; effective if the reduction in score was between 30 and $60 \%$, and ineffective if the reduction in score was lower than $30 \%$. Total response to treatment (TRT) was calculated as in Eq 1.

$\operatorname{TRT}(\%)=\{(\mathrm{Ns}+\mathrm{Ne}) / \mathrm{Nt}\} 100$

where $\mathrm{Ns}=$ no. of significantly effective cases, $\mathrm{Ne}=$ no. of effective cases, and $\mathrm{Nt}=$ total no. of cases.

\section{Statistical analysis}

Measurement data are expressed as mean $\pm \mathrm{SD}$, and were statistically analyzed using two independent sample t-test. Enumeration data are expressed as \% were analyzed with Chi-square test. All statistical analyses were done with SPSS version 20.0. Difference was assumed to be statistically significant at $p<0.05$.

\section{RESULTS}

\section{Clinical profile of subjects}

There was no significant difference in general data between the two groups $(p>0.05)$. Thus, the two groups were comparable (Table 1).

\section{Clinical efficacy of treatment}

The total response of the study group was 97.83 $\%$, which was significantly higher than that of the control group (69.57\%, $p<0.05$, Table 2$)$.

\section{Comparative clinical scores}

There were no significant differences in the scores for MMSE, ADAS-cog, CDR, ADL, NPI and CMAl between the two groups before treatment $(p>0.05)$.

However, after treatment, all scale scores were improved, and the MMSE score in the study group was significantly higher than that in the control group, while the scores for ADAS-cog, CDR, ADL, NPI and CMAI in the study group were significantly lower than those in the control group $(p<0.05$, Table 3$)$.

\section{Adverse reactions}

The incidence of adverse reactions in the study group was $6.52 \%$, which was significantly lower than that in the control group $(34.78 \%, p<0.05$, Table 4).

Table 1: Clinical profile of subjects

\begin{tabular}{lcccc}
\hline Group & Study & Control & t/ $\mathbf{X}^{2}$ & $\boldsymbol{P}$-value \\
\hline Age (years) & $66.42 \pm 4.86$ & $67.22 \pm 7.93$ & 0.271 & $>0.05$ \\
Sex (Male/Female) & $26 / 20$ & $28 / 18$ & 0.196 & $>0.05$ \\
Weight (kg) & $61.3 \pm 5.24$ & $60.4 \pm 5.32$ & 0.067 & $>0.05$ \\
Body mass index (BMI) $\left(\mathrm{kg} \cdot \mathrm{m}^{-2}\right)$ & $58.54 \pm 4.55$ & $58.59 \pm 4.62$ & 0.079 & $>0.05$ \\
Heart rate (HR) (beat $\left.\cdot \mathrm{min}^{-2}\right)$ & $75.10 \pm 7.32$ & $74.73 \pm 6.96$ & 0.234 & $>0.05$ \\
Systolic blood pressure (SBP) $(\mathrm{mmHg})$ & $106.91 \pm 8.89$ & $107.29 \pm 9.21$ & 0.192 & $>0.05$ \\
Diastolic blood pressure (DBP) $(\mathrm{mmHg})$ & $77.89 \pm 2.41$ & $76.92 \pm 3.01$ & 0.386 & $>0.05$ \\
\hline
\end{tabular}

Table 2: Clinical efficacy treatments, N (\%)

\begin{tabular}{lcccc}
\hline Group & Study & Control & $\mathbf{X}^{2}$ & $\boldsymbol{P}$-value \\
\hline Significantly effective & $28(60.87)$ & $12(26.09)$ & & \\
Effective & $17(36.96)$ & $20(43.48)$ & & \\
Ineffective & $1(2.17)$ & $14(30.43)$ & & \\
Total response rate & $45(97.83)$ & $32(69.57)$ & 12.317 & $<0.05$ \\
\hline
\end{tabular}


Table 3: Clinical scores for subjects

\begin{tabular}{lcccc}
\hline \multirow{2}{*}{ Parameter } & \multicolumn{2}{c}{ Study } & \multicolumn{2}{c}{ Control } \\
\cline { 2 - 5 } & $\begin{array}{c}\text { Before } \\
\text { treatment }\end{array}$ & After treatment & $\begin{array}{c}\text { Before } \\
\text { treatment }\end{array}$ & After treatment \\
\hline MMSE & $14.81 \pm 4.31$ & $24.26 \pm 4.86^{* \#}$ & $15.32 \pm 4.08$ & $20.12 \pm 4.05$ \\
ADAS-cog & $37.40 \pm 5.16$ & $22.63 \pm 5.64^{* \#}$ & $38.82 \pm 7.21$ & $27.01 \pm 5.12$ \\
CDR & $3.13 \pm 0.18$ & $1.55 \pm 0.37^{\star \#}$ & $3.21 \pm 0.62$ & $2.02 \pm 0.14^{\star}$ \\
ADL & $46.23 \pm 9.01$ & $37.15 \pm 7.86^{* \#}$ & $46.95 \pm 8.65$ & $40.84 \pm 7.30^{*}$ \\
NPI & $35.72 \pm 7.19$ & $23.52 \pm 5.87^{\star \#}$ & $36.14 \pm 7.13$ & $32.12 \pm 6.21^{*}$ \\
CMAI & $48.50 \pm 5.60$ & $27.87 \pm 3.05^{\star \#}$ & $48.35 \pm 5.30$ & $36.29 \pm 3.82$ \\
\hline
\end{tabular}

Results are shown as mean \pm SD. ${ }^{*} p<0.05$, compared with value before treatment; ${ }^{\#} p<0.05$ compared with control group

Table 4: Comparison of adverse reactions (\%)

\begin{tabular}{lcccc}
\hline Group & Study & Control & $\mathbf{X}^{2}$ & $P$-value \\
\hline Dry mouth & $1(2.17)$ & $5(10.87)$ & & \\
Somnolence & $1(2.17)$ & $4(8.70)$ & & \\
Dizzy & $0(0)$ & $4(8.70)$ & & \\
Constipation & $1(2.17)$ & $1(2.17)$ & & \\
Insomnia & $0(0)$ & $1(2.17)$ & & \\
Gain weight & $0(0)$ & $1(2.17)$ & & \\
Total adverse reactions & $3(6.52)$ & $16(34.78)$ & 11.458 & $<.05$ \\
\hline
\end{tabular}

\section{DISCUSSION}

Nowadays, ageing of the Chinese population is on the increase. Alzheimer's disease is a common disease among the elderly. Thus, the number of patients with Alzheimer's disease in China is increasing year by year $[13,14]$. Alzheimer's disease is manifested as irreversible impairment in cognition and memory, Therefore, the disease has extremely poor prognosis [15]. Elderly people have poor drug absorption and tolerance. A lot of research interest is currently focused on delaying the development of Alzheimer's disease and improving the cognitive ability of patients with drug therapy [16].

Relevant data show that positive symptoms of mental disorder patients appear before cognitive impairment and slight cognitive impairment has occurred even in childhood. Therefore, several studies have found that cognitive impairment is a marker of mental disorder, and cognitive function testing accurately reflects the extent and degree of cognitive impairment in Alzheimer's disease patients with mental disorders $[17,18]$. In this study, the study group had significantly higher MMSE score than the control group, while scores in ADAS-cog, CDR, ADL, NPI and CMAI were significantly lower. These results show that the aripiprazole-olanzapine combination treatment mitigated the mental symptoms of Alzheimer's disease patients and inhibited the development of the disease, which is in line with the results of a previous study [19].
Olanzapine is a 5-hydroxytryptamine and dopamine receptor antagonist. By blocking D2 and $5-\mathrm{HT} 2 \mathrm{~A}$ receptors and reducing the release of dopamine, olanzapine reduces schizophrenic manifestations such as negative symptoms, cognitive disorder, positive disorder and affective disorder [20]. Aripiprazole is a third generation of atypical anti-psychotic drug. It is a quinoline derivative and a D2 and $5 \mathrm{HT} 1 \mathrm{~A}$ receptor agonist. It completely antagonizes 5 HT2A receptor and antagonizes some $5 \mathrm{HT} 2 \mathrm{~A}$ receptor agonists. Thus, aripiprazole relieves patients' psychiatric symptoms, increases dopamine in low excitation state, promotes improvement of negative symptoms, and repairs cognitive function deficits. Moreover, aripiprazole maintains normal physiological function of dopamine [21]. In the course of treatment, it regulates the agonist antagonism of dopamine neurons in vivo as a function of neurotransmitter levels, thereby mitigating the symptoms of Alzheimer's disease and, enhancing therapeutic effects [22].

The combination of the two drugs improved the conditions of elderly patients with Alzheimer's disease and mental disorders by reducing excessive DA function in the midbrain limbic system pathway without affecting the cognitive function. The results of this study showed that the study group had significantly better therapeutic effect than the control group. This indicates that aripiprazole-olanzapine combined treatment significantly improved therapeutic effect in the treatment of elderly patients with 
Alzheimer's disease and mental disorders, when compared with olanzapine alone.

The results of this study showed that the incidence of adverse reactions in the study group was significantly lower than that in the control group. This suggests that the combination of aripiprazole and olanzapine reduced the incidence of adverse reactions and improved quality of life in elderly patients with Alzheimer's disease complicated with mental disorders. This finding is similar to the research results of Liu et al [23]. It is likely that aripiprazole antagonized 5hydroxytryptamine $1 \mathrm{~A}$ receptor, reduced the activity of nigrostriatal pathway, reversed the antagonism of D2 receptor of substantia nigrastriatum pathway, and controlled the side effects of olanzapine.

\section{Limitations of the study}

The incidence of adverse reactions in the two groups was low, which might be related to the small sample size. Therefore, the safety of drug use remains to be further studied with larger sample sizes. Moreover, the influence of length of treatment course is a problem which needs to be considered in subsequent studies.

\section{CONCLUSION}

Aripiprazole-olanzapine combination is effective in the treatment of senile Alzheimer's disease complicated with mental disorders, and is superior to the use of olanzapine. It improves the mental capacity and cognitive functions of patients, and it has high degree of safety.

\section{DECLARATIONS}

\section{Conflict of interest}

No conflict of interest is associated with this work.

\section{Contribution of authors}

We declare that this work was done by the authors named in this article and all liabilities pertaining to claims relating to the content of this article will be borne by the authors.

\section{Open Access}

This is an Open Access article that uses a funding model which does not charge readers or their institutions for access and distributed under the terms of the Creative Commons Attribution License (http://creativecommons.org/licenses/by/
4.0) and the Budapest Open Access Initiative (http://www.budapestopenaccessinitiative.org/rea d), which permit unrestricted use, distribution, and reproduction in any medium, provided the original work is properly credited.

\section{REFERENCES}

1. Dubois B, Feldman HH, Jacova $C$, Hampel $H$, Molinuevo JL, Blennow K, DeKosky ST, Gauthier S, Selkoe D, Bateman $R$, et al. Advancing research diagnostic criteria for Alzheimer's disease: the IWG-2 criteria. Lancet Neurol 2014; 13(6): 614-629.

2. Norton S, Matthews FE, Barnes DE, Yaffe K, Brayne C. Potential for primary prevention of Alzheimer's disease: an analysis of population-based data. Lancet Neurol 2014; 13(8): 788-794.

3. Tapiainen $V$, Hartikainen $S$, Taipale $H$, Tihonen J, Tolppanen AM. Hospital-treated mental and behavioral disorders and risk of Alzheimer's disease: A nationwide nested case-control study. Eur Psychiatry 2017; 43: 9298.

4. Piersol CV, Canton K, Connor SE, Giller I, Lipman S, Sager S. Effectiveness of interventions for caregivers of people with Alzheimer's disease and related major neurocognitive disorders: a systematic review. Am J Occup Ther 2017; 71(5): 710580020p1$7105180020 p 10$.

5. Cui Y, Wu QH, Hao YH, Wang DC, Kang Z. Alzheimer's disease-related risk factors. Chin Gener Pract 2012; 15(26): 3000-3002.

6. Kumar A, Ekavali AS. A review on Alzheimer's disease pathophysiology and its management: an update. Pharmacol Rep 2015; 67(2): 195-203.

7. Dimer FA, Ortiz M, Pase CS, Roversi K, Friedrich RB, Pohlmann AR, Burger ME, Guterres SS. Nanoencapsulation of olanzapine increases its efficacy in antipsychotic treatment and reduces adverse effects. J Biomed Nanotechnol 2014; 10(6): 1137-1145.

8. Vigen CL, Mack WJ, Keefe RS, Sano M, Sultzer DL, Stroup TS, Dagerman KS, Hsiao JK, Lebowitz BD, Lyketsos CG, et al. Cognitive effects of atypical antipsychotic medications in patients with Alzheimer's disease: outcomes from CATIE-AD. Am J Psychiatry 2011; 168(8): 831-839.

9. Pae CU, Forbes A, Patkar AA. Aripiprazole as adjunctive therapy for patients with major depressive disorder: overview and implications of clinical trial data. CNS Drugs 2011; 25(2): 109-127.

10. Declaration of Helsinki. The 59th World Medical Conference, 2008.

11. Society of Neurology, Chinese Medical Association. Chinese Classification and Diagnostic Criteria for Mental Disorders, 3rd Edition (Classification of Mental Disorders). Chin J Psychiatry 2001; 34(3): 59-63.

12. O'Regan J, Lanctot KL, Mazereeuw G, Herrmann N. Cholinesterase inhibitor discontinuation in patients with 
Alzheimer's disease. J Clin Psychiatry 2015; 76(11): 1424-1431.

13. Lunnon K, Smith $R$, Hannon E, De Jager PL, Srivastava G, Volta M, Troakes C, Al-Sarraj S, Burrage J, Macdonald $R$, et al. Methylomic profiling implications cortical deregulation of ANK1 in Alzheimer's disease. Nat Neurosci 2014; 17(9): 1164-1170.

14. Karch CM, Goate AM. Alzheimer's disease risk genes and mechanisms of disease pathogenesis. Biol Psychiat 2015; 77(1): 43-51.

15. Kumar V, Anand R, Messina J, Hartman R, Veach J. An efficacy and safety analysis of Exelon in Alzheimer's disease patients with concurrent vascular risk factors. Eur J Neurol 2000; 7(2): 159-169.

16. Corbett A, Smith J, Creese B, Ballard C. Treatment of behavioral and psychological symptoms of Alzheimer's disease. Curr Treat Options Neurol 2012; 14(2): 113125.

17. Eskici G, Axelsen PH. Copper and oxidative stress in the pathogenesis of Alzheimer's disease. Biochem 2012; 51(32): 6289-6311.

18. Tang $L N, X U X M, L i Y H$. Research progress on the pathogenesis of Alzheimer's disease. Chin J Gerontol 2016; 36(10): 2545-2548.
19. Fu X, Qin XX. Clinical efficacy and safety of aripiprazole combined with olanzapine in the treatment of elderly Alzheimer's disease with mental disorders. Chin J Clin Pharmacol 2016; 32(7): 609-611.

20. Xue $X$, Song $Y$, $Y u X$, Fan $Q$, Tang J, Chen $X$. Olanzapine and haloperidol for the treatment of acute symptoms of mental disorders induced by amphetamine-type stimulants: $A$ randomized controlled trial. Medicine 2018; 97(8): e9786.

21. Lin CY, Tsai GE, Wang HS, Wu YH, Chiou CC, Wu VY, Lane HY. Effectiveness of aripiprazole, olanzapine, quetiapine, and risperidone augmentation treatment for major depressive disorder: a national wide populationbased study. Clin Psychiatry 2014; 75(9): 924-931.

22. De Deyn PP, Drenth AF, Kremer BP, Oude Voshaar RC, Van Dam D. Aripiprazole in the treatment of Alzheimer's disease. Expert Opin Pharmacother 2013; 14(4): 459474.

23. Liu HB, Li XQ, Hou LF. Safety and cost-effectiveness analysis of aripiprazole and olanzapine in the treatment of first-episode schizophrenia. Mod J Integr Tradit Chin West Med 2015; 24(27): 2999- 3001. 